\title{
When a House Is Not a Home
}

\author{
ANNE GARTNER \\ Royal Melbourne Institute of Technology \\ Australia
}

\begin{abstract}
There has been growing interest in exploring the concept of home, especially the relationship between house, the dwelling and the local area, but seldom from the point of view of the dispossessed. This paper describes a large Australian research study which focusses on homeless youth's perception of house and home in a suburban area with much "hidden" homelessness. The interview material points to the heterogeneity of perceptions of homeless youth, describing many dimensions of the meaning of home. The findings which emerge from this study will be used to inform the design of future support services and accommodation provision.
\end{abstract}

This paper examines the distinction between house and home. It is informed by my current involvement in two projects (i) a large scale study of homeless youth (aged 1625) in an outer suburban municipality of Melbourne' and (ii) an RMIT "Homeless Youth" architecture studio in which the brief was to design accommodation for homeless secondary school students ${ }^{2}$. Whereas many built environment professionals work with narrow, taken-for-granted categories of home and homelessness this paper emphasises the heterogeneity of meanings of home, the irregular correlation between physical reference points and a concept of home and the design implications which follow from a broader understanding of home.

Social science research from the 1980 s has highlighted many underlying difficulties with prevailing definitions of house, home and homelessness ${ }^{3}$. For example homelessness used to be a taken-for-granted category referring to "no roof". However recent housing studies have shown that for some people an apparently adequately designed house may provide an insecure and unstable everyday living environment with none of the warm, cosy associations of home. Victims of domestic violence or incest, for example, may have an official address and shelter but a negative and stressful perception of their house. More frequently, with changing trends in family cohesiveness, mothers and fathers may order their children to leave the parental house or children may leave a family environment which they perceive as unsupportive. These children might still retain an "official" address with their family of origin.

Because of these complexities our research works with a broad definition of homelessness:

Homelessness describes a lifestyle which includes insecurity and transiency of shelter. It is not confined to a total lack of shelter. For many children and young people it signifies a state of detachment from family and vulnerability to dangers, including exploitation and abuse broadly defined, from which the family normally protects the child. ${ }^{4}$

Consequently a homeless (young) person may be living without physical shelter, or with the threat of losing their shelter, or may be moving frequently between different kinds of accommodation, or may be living in places which are inadequate due to crowding or poor physical provision, lack of support, security or stability. ${ }^{5}$ The physical environment of the homeless may be a squat, the street, a caravan, the family house, emergency accommodation or a friend's house.

Space does not permit a full outline of the scope of the research project. Imstead this paper focusses on a central issue - how homeless youth perceive home. What is clear from our research is that many of the stereotypes relating to homelessness and homeless people in Australia are inaccurate. (Part of our rationale for working in an outer suburban locality was to question the prevailing belief that homelessness is predominantly located in the inner city.) So far we have found that homeless youth are not necessarily visible in public spaces and that their presence tends to be uncierestimated in outer suburban localities. They are not necessarily street kids in their dress or orientation, they are not necessarily isolates (on the contrary isolates stand as the exception) and they express a strong affiliation and identification with their local area. Frequently they tell articulate and individual stories about their housing circumstances, maintain some contact with their family and are reflective about their dislocated housing, schooling and social experiences. 
In contrast to the European experience, Australian homeless youth exhibit little political involvement or interest towards others disenfranchised in the housing market, whether expressed in politicised examples of squatting, graffiti or collective action ${ }^{6}$. Some familiar patterns are also emerging , which accord more generally with homeless research. Homeless youth tend to come from very geographically mobile families from a range of class backgrounds - army personnel, employment seekers, business people who work for multi-national companies, families with eviction or rental problems in the private rental sector. They experience difficulties with split and blended family backgrounds often following a more settled period in early childhood. Some follow established family patterns of welfare dependence.

Our research was partly shaped by acknowledging many of the difficulties which have faced investigators of housing and homeless issues. Welfare recipients, including some homeless, tend to have been interviewed extensively and have developed stock answers to describe their housing circumstances. Fruitful questions relating to housing and the meaning of home are notoriously difficult to construct. Assumptions about the importance of the physical characteristics of a house are often embedded in questions. However research from sociology, environmental psychology and cognitive geography points to a broad range of social and environmental response. For example a home may be conceived variously as a haven, as a material shelter (Fig. 1), as a physiological shelter, as "here and now", as an ideal, as work, as part of an individual's identity, or as an expression of the integration of the individual with the family and society.

Bearing these issues in mind a research tool was developed for the Ringwood study drawing on elements of Clare Cooper Marcus' environmental biography. ${ }^{7}$ As an introduction to the semistructured interview two key drawings were requested :

- Can you draw the place where you have been happiest?

- Can you draw the place where you would most like to live?

Utilising techniques from participatory design approaches, the homeless sample was encouraged to talk while drawing, to describe relevant material and contextual information which was difficult to draw, and to refer to details of the drawings during the following interview.

Detailed information on conceptions of house and home were obtained using this approach, noting that some interviewees chose not to include any reference to a house. The drawings brought out layers of unexpected associations and memories for the interviewees in a way with does not necessarily occur with words alone. This technique elicited more detailed responses than conventional interview questions on housing. It appears to be an approach which, when undertaken with care, leads into forgotten layers of memory and a desire to elaborate on information in the interview setting. The themes, content and interview text are subsequently being analysed for information about
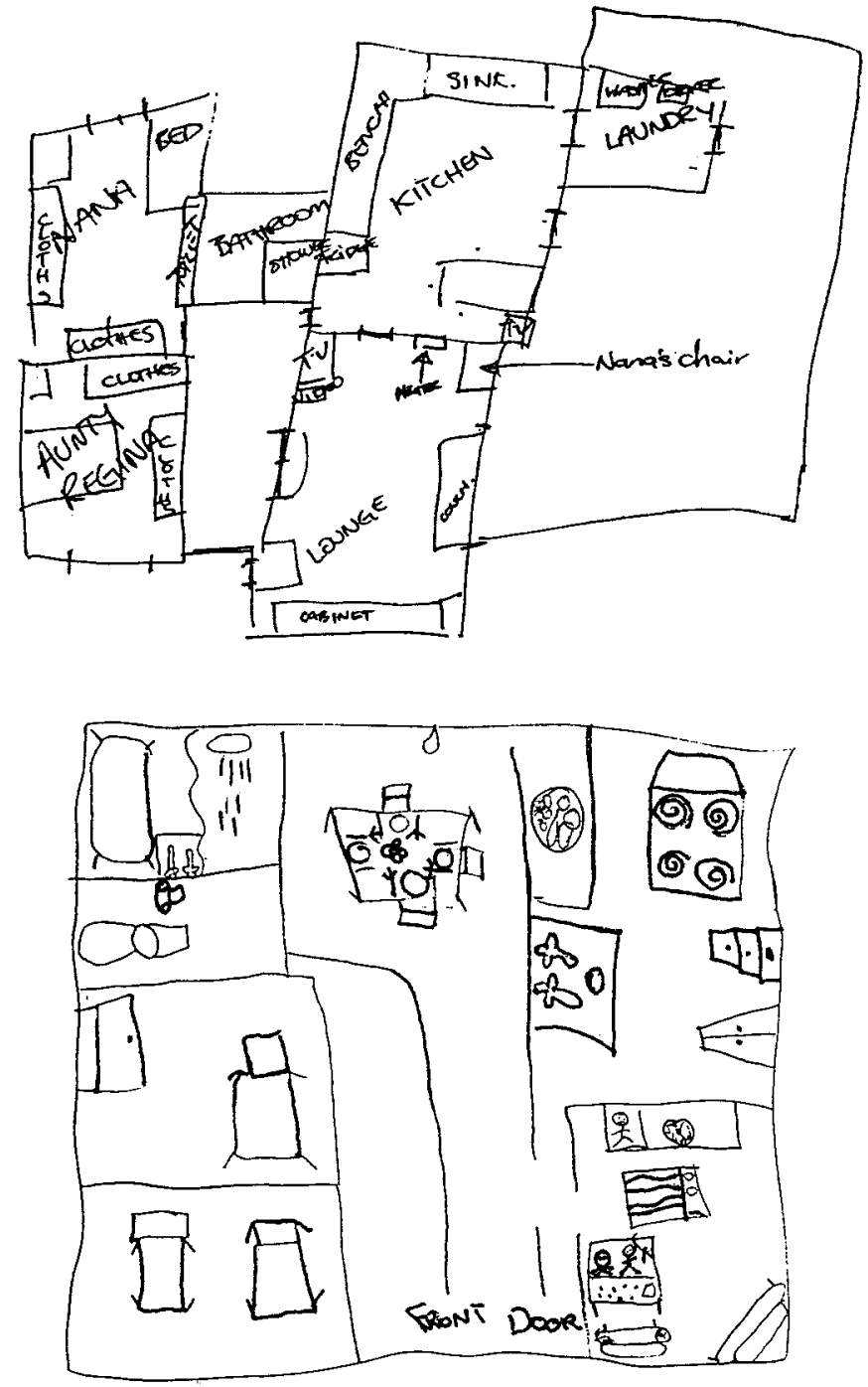

Fig. 1. Two versions of home depicted as a material shelter, with an emphasis on the spatial layout of rooms and furnishings.

how the homeless ordered their environment, the urban scale which is significant to them, the relationship between indoor and outdoor spaces and their conception of house and home.

Interpretation of the drawings and text reveals a very different view of the built environment from the traditional architectural view which tends to emphasise the physical and symbolic aspects of shelter. While there is limited research data pertinent to the analysis of drawn responses by a homeless group, psychological research of the 16-25 age group would lead us to expect the following biases. Searles found that adolescents would be more likely to prefer "intimacy with an idealised vision of nature to human

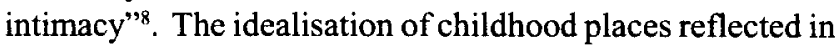
their drawing may also be a response to a sense of entrapment. Youth are more likely to emphasise significant emotional experiences while growing up at the expense of the physical setting; spaces away from home might be 
recalled more favourably when needs for nurturance and caring were not fully met in the family. ${ }^{9}$

These findings would lead us to predict that homeless youth would be very likely to produce ideal images of home and to draw built and "natural" spaces which do not include the family home. However, as will be evident in the following thematic analysis of the drawings, there were also similarities between the drawings of the homeless and the material in environmental autobiographies of tertiary students $^{10}$ (who are not homeless) in a similar age range. Drawings from both groups reveal the strong emotive association of spaces beyond adult control, outdoor places, self built and manipulated spaces in left over territory, as well as the importance of hidden spaces from which it is possible to observe the world withour being observed. Direct and indirect information about house and home emerges from the analysis.

\section{CAN YOU DRAW THE PLACE WHERE YOU HAVE BEEN HAPPIEST?}

About one half of the drawings of the homeless sample depict the house of the family of origin or of a close relative (frequently grandparents) as their happiest place. The way these houses are drawn reveal different ways of perceiving the significance of house and setting : as an internal division of room space and/or garden space (functional plan), as a package of furnishings and equipment (physical amenity), as a space for relationships with pets or family members (heart), as a house type, for example a high rise flat, a caravan, an institutional setting (shelter) or as a setting for a specific social occasion, for example around the tree at Christmas time. The spatial and temporal dimensions vary considerably.

Another fifth of the sample drew an outdoor location usually near water - camping, surfing or a beach. In descending frequency a "here and now" theme was drawn (a coat, a bed), followed by a previous institutional or foster home. Lastly, many scattered individual responses depicted places dissimilar to the family home - theme parks (often visited on one occasion), a football field, "my boyfriends arms", station steps and the hospital room "where I had my baby".

\section{CAN YOU DRAW THE PLACE WHERE YOU WOULD MOST LIKE TO LIVE?}

This question, likely to elicit a more idealised response, revealed three major clusters of responses : (i) a large house and garden, (ii) a rural environment (often depicted as a farm with a range of animals, a stream, a sprawling timber cottage, mountains in the background - Fig. 2) or (iii) a beach setting (frequently tropical locations like Hawaii or Queensland). The remaining minority responses were again diverse : surfing, in the clouds, a castle overlooking Loch Ness, a caravan park, a fairy bedroom were examples.

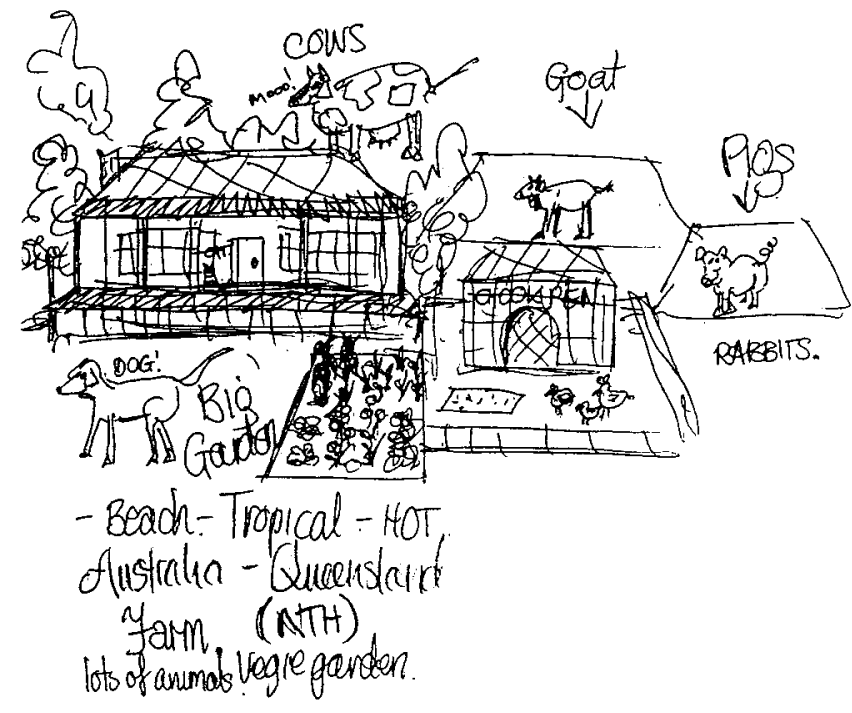

Fig. 2. An example of an idealized home in a rural setting, stressing relationships to animals

The spatial and temporal dimensions within the large house and garden cluster again varied considerably, as well as replicating the noted diversity of meanings of home. Some images were drawn as a plan or a front elevation, others as a series of leisure amenities or a set of furniture and equipment. The scale extended from a single room to the contextual landscape. Many of the drawings were of luxuriously appointed houses situated near the sea/rivers, in tropical settings or with lots of animals and pets. The built form included large detached houses, inner city terrace houses and farm houses. In some cases the present dwelling was described. Occasionally the large houses were modelled on memories of a friend's house. Many of these designs also show a clear affiliation with mainstream housing taste, very different to the current accommodation of the homeless. These houses have long driveways, double garages, swimming pools and spas, play equipment and a "standard" package of furnishings including hi-fi, fridge, microwave, kitchen equipment, very similar to outer suburban detached display houses currently publicised in sales brochures (Fig. 3). They represent mainstream Australian housing taste.

Our future research will examine the drawings in greater depth, firstly in terms of detail and technique, and secondly within the context of the transcriptions of the interviews. However some major themes about house and home are already emerging. Typically the drawings are relatively unpeopled but many include archetypal details of home (chimneys, hipped rooves, picket fences, roses, water, log cabins in the rural settings). However the experience of homelessness is reflected in few house and home oriented images associated with the family of origin. Places which have been significant for a only a few hours have even been depicted! The drawings (and text) point to a diversity of preferred places and settings described by homeless youth 


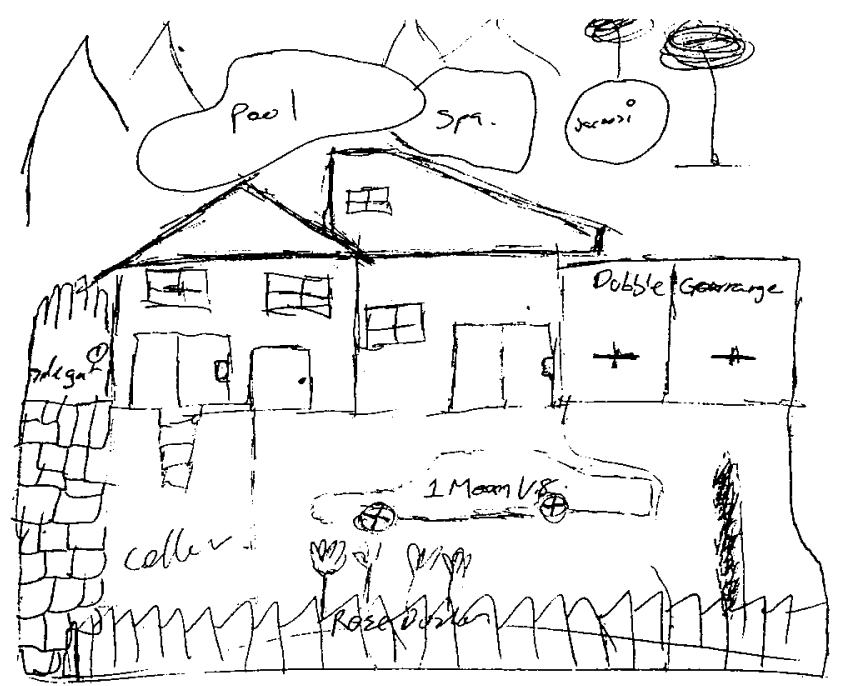

Fig. 3. An example of an idealized home with material characteristics very similar to mainstream housing aspirations.

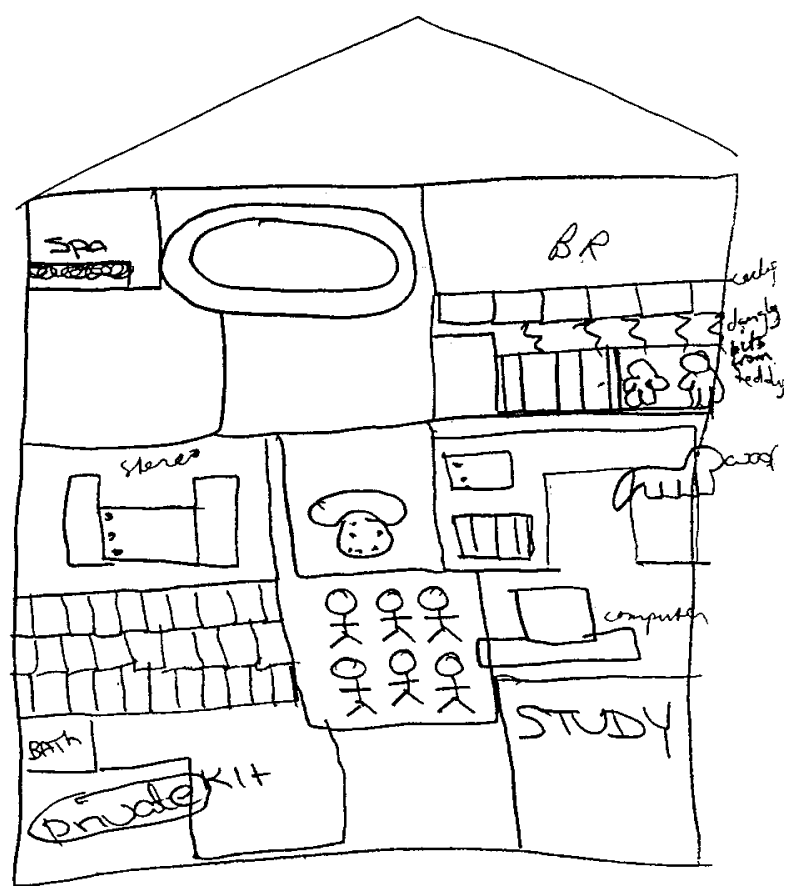

Fig. 4. Danielle's drawing of her ideal place which combines lavish material features and extreme security and privacy needs.

which augment the categories used to describe the possible dimensions of "home". The importance of the locality rather than the individual house, home as a base for external activity, home as a place to maintain a close relationship with pets, home as a site of questioning about relationships and possessions, or home as a site for rules, regulation and discipline are among the new categories emerging from our research. These meanings can be added to the conceptions of home identified earlier in this paper.

A good example of the complexity of the images of house and home comes from Danielle. Her drawing of the place where she would most like to live is a large house with many bedrooms, a computer room, a spa and swimming pool, unconventionally portrayed in a combined elevation and plan (Fig. 4). She includes many bars, underpinning her need for security, control and the opportunity for guarding her space. Her interview records contradictory responses; that she wants a house where she can't be touched or hurt, with bars so no one can get in, that has heaps of bedrooms just in case some of her friends (her cats!) do not have anywhere to go and a big kitchen which is also a private room which can be locked. " Crisis accommodation for Danielle would need to emphasise qualities like enclosure and security over "heart" and "hearth" dimensions, or particular architectural qualities, to meet her current preferences.

Although this research is still in progress it suggests that great care is needed when devising the physical and social design criteria for crisis and longer term accommodation for homeless youth. The policies leading towards deinstitutionalisation currently favoured in many western countries should be sensitive to the diversity of housing responses which our research is uncovering. It is a big challenge to design a temporary "home" for those who feel they have never had one, or even for the youth in our sample who claim that "design doesn't matter to them".

Given these findings architects designing crisis acommodation need to anticipate an extreme diversity of "home"needs in one building. Designers, whether professionals or students, also should carefully examine the cultural and conceptual bases of their own notions of home to avoid inappropriately imposing them on their clients.

In conclusion, introducing this complexity about the meaning of house and home into the "Homeless Youth" studio was a difficult task. The students came from first to forth year and were from diverse cultural backgrounds. During one semester it was difficult to sensitise them to the many relevant social and design issues involved with housing for the homeless. The experience early in the semester of visiting a range of hostels and emergency accommodation and speaking with homeless secondary students helped to break down many stereotypical views held by the students of "hopeless druggies" and "bums". Unfortunately it was often easier for students to project their own housing preferences, reproducing their own bedrooms and bathrooms and living spaces, without working to the realities of a tight welfare budget or the needs of homeless youth. Even those students who had personal experience of insecure housing had difficulty empathising with the experience of homeless students. The studio coordinator felt that many first year students needed to "get their ideal house out of their system" before coming to grips with the demands of the studio. From my perspective as a social consultant the students appeared to design from the walls in. Only after the walls had been located on the site, thereby largely predetermining the organisation of the accommodation, were students able to grapple with ideas which challenged their understanding of house and home. 


\section{NOTES}

1 This qualitative research project involves three RMIT researchers : Anne Gartner, Erica Hallebone and Llewellyn Johns in the Department of Social Science, run with the co-operation of Wesley City Mission in Ringwood, a low density regional centre, thirty kilometers from the CBD. The research is substantially funded by the Commonwealth Department of Health and Community Services and is studying the relationship between health, housing and personal identity. The material described in this paper refers to only part of the ongoing project.

2 The "Homeless Youth" studio is co-ordinated by Ann Rado with an interdisciplinary team of architects, landscape architects, social scientists and a youth worker engaged with homeless students. This studio has been given special relevance by a recently released census of homeless secondary students which estimates that between 25,000-30,000 Australian students may be homeless during one year. D. MacKenzie and C. Chamberlain, 'The National Census of Homeless School Students', Youth Studies Australia, Autumn 1995.

${ }^{3}$ See for example P. Somerville, 'Homelessness and the Meaning of Home : Rooflessness or Rootlessness?', International Journal of Urban and Regional Research, Vol 16, No 4, 1992; S. Watson and H. Austberry, Housing and Homelessness : $A$
Feminist Perspective, Routledge and Kegan Paul, London, 1986, , S. Sixsmith, 'The Meaning of Home : An Exploratory Study of Environmental Experience', Journal of Environmental Psychology, No 6, 1986; A. Sicinski and P. Lukasiewicz, 'Home - Its Contempory Material, Social and Value Aspects', The First International Conference on Home, Warsaw, 1990; Altman and C. Werner (eds), Home Environments, Plenum Press, London and New York, 1985.

${ }^{4}$ Human Rights and Equal Opportunity Commission , Our homeless children : report of the National Inquiry into Homeless Children, AGPS, Canberra, 1989, p. 7.

s C.Hurst, Forced Exit, Youth Homelessness Policy Development Project, Salvation Army, October 1989.

6 E. Hallebone, 'Homelessness and Marginality', X111 World Congress of Sociology, Bielefeld, Germany, July 1994.

${ }^{7}$ C. Cooper Marcus, Environmental Autobiography, Working Paper, Institute of Urban and Regional Development, University of California, Berkeley, 1979.

${ }^{8}$ H. Searles in I. Altman and S. Low (eds), Place Attachments, Plenum Press, New York and London,1992, p. 72.

9 L. Chawla, 'Childhood Place Attachments' in I. Altman and S. Low, pp. 75-77.

10 C. Cooper Marcus, 'Remembrance of Landscapes Past', Landscape, Vol 22, No 3, 1975.

"Interview, homeless youth research project. 